\title{
PRÁTICAS CONSTITUINTES DE INVESTIGAÇÃO PLANEJADA POR ESTUDANTES EM AULA DE CIÊNCIAS: ANÁLISE DE UMA SITUAÇÃO
}

\author{
Lúcia Helena Sasseron
}

https://orcid.org/0000-0001-5657-9590

\section{RESUMO:}

Nos últimos anos muito se tem discutido sobre o ensino de ciências como prática que possibilite relação com as dimensões conceitual, social, material e epistêmica do conhecimento. Neste estudo de caso, com análise qualitativa, estudamos uma situação de ensino em atividade eletiva em que estudantes dos anos iniciais do Ensino Fundamental, sob a supervisão de monitores com formação em diferentes áreas das ciências, se envolvem no planejamento de investigação. A partir do estudo, identificamos elementos constituintes da investigação e como eles se relacionam aos objetos epistêmicos e às condições experimentais. Entendemos que os resultados apresentados podem contribuir para a pesquisa em Educação em Ciências por expor um modo de análise de situações de investigação em que práticas epistêmicas são realizadas pelos estudantes.

\section{CONSTITUTIVE PRACTICES OF INQUIRY PLANNED BY STUDENTS IN SCIENCE LESSON: ANALYSIS OF AN EXAMPLE}

\begin{abstract}
:
In recent years, much has been discussed about the teaching of science as a practice allowing relations among conceptual, social, material and epistemic dimensions of knowledge. In this case study, with qualitative analysis, we analyzed a teaching situation in elective activity in which Elementary School students, under the supervision of monitors trained in different areas of science, get involved in an inquiry planning. From the study, we identified constituent elements of the investigation and how they relate to epistemic objects and experimental conditions. The results presented in this paper can contribute to Science Education research area by exposing a way of analyzing research situations in which epistemic practices are performed by students.
\end{abstract}

\section{PRÁCTICAS CONSTITUTIVAS DE UNA INVESTIGACIÓN PLANIFICADA POR ALUMNOS EN LA CLASE DE CIENCIAS: ANÁLISIS DE UNA SITUACIÓN}

\section{RESUMEN:}

En los últimos años se ha discutido sobre la enseñanza de las ciencias como una práctica que permite relacionar las dimensiones conceptual, social, material y epistémica del conocimiento. En este estudio de caso, con análisis cualitativo, investigamos una situación de enseñanza en una actividad optativa en la que alumnos de los ciclos iniciales de la educación primaria, bajo la supervisión de monitores formados en diferentes áreas de las ciencias, se
Palavra-chave:

Ensino por investigação;

Práticas epistêmicas;

Ensino Fundamental.

Keywords:

Inquiry-based teaching;

Epistemic practices;

Elementary school.

Palabras clave:

Enseñanza por

investigación;

Prácticas epistémicas;

Educación Primaria. 
involucran en la planificación de la investigación. A partir del análisis, identificamos elementos que componen la investigación y cómo se relacionan con los objetos epistémicos y las condiciones experimentales. Creemos que los resultados presentados pueden contribuir a la investigación en Educación Científica al exponer una forma de analizar situaciones de investigación en las que los estudiantes realizan prácticas epistémicas.

\section{INTRODUÇÃO}

A área de pesquisa em Educação em Ciências, há mais de meio século, em todo o mundo, tem indicado que as Ciências da Natureza ${ }^{1}$ devem ser apresentadas em sala de aula na relação entre os temas conceituais e as práticas de experimentação, exploração e investigação (Carvalho, 2018; Duschl, 2008; Jiménez-Aleixandre \& Crujeiras, 2017; Kelly \& Licona, 2018; Lehrer \& Schauble, 2006; Stroupe, 2014).

Em um ensaio sobre reformas do ensino de ciências, Krasilchick (2000) mostra que as mudanças no currículo desta disciplina têm forte relação com os cenários político, social e científico; e identifica e estabelece relações entre os objetivos do ensino, as concepçóes de ciência vigentes e as modalidades didáticas recomendadas. Em perspectiva semelhante, outros estudos identificam relações entre concepçôes sobre ciência e seus modos de construir conhecimento e os modos de estruturar seu ensino (Chinn \& Malhotra, 2002; Lehrer \& Schauble, 2006; Stroupe, 2014). De modo sintético, Lehrer e Schauble (2006) afirmam que, historicamente, as concepçóes transitaram de ciência como acúmulo de conhecimento, para ciência como mudança conceitual, chegando à ciência como lógica. Diante de tal panorama, para os dias atuais, eles propóem o ensino dessa disciplina na relação com a concepção de ciência como prática. Para esta perspectiva, fatos, dados, teorias são tão importantes quanto o contexto e as condiçốes de proposição de um conhecimento, assim como também são relevantes os processos realizados para esta proposição, sua apresentação e análise.

Movimentos curriculares em todo o mundo têm se pautado em resultados de pesquisa e proposto caminhos que dialogam, em maior ou menor intensidade, com ideias como as mencionadas anteriormente. No Brasil, a publicação do novo documento curricular, a BNCC - Base Nacional Comum Curricular, indica, para a área de Ciências da Natureza, a necessidade de que os estudantes tenham "acesso à diversidade de conbecimentos cientificos produzidos ao longo da história, bem como a aproximação gradativa aos principais processos, práticas e procedimentos da investigação cientifica”(Brasil, 2017, p. 319, grifos no original).

Não é o escopo deste artigo analisar documentos oficiais tampouco esboçar exemplos sobre como torná-los concretos em situações de ensino. Entretanto, é importante pontuar a ênfase explícita à investigação científica no documento curricular e, com isso, a partir dos aspectos reconhecidos por antropólogos e sociólogos das ciências como associados à atividade científica (Knorr-Cetina, 1999; Latour \& Woolgar, 1986; Longino, 1990, 2002; Pickering, 1995), dialogar com as perspectivas atuais da pesquisa da área em que as práticas epistêmicas surgem como maneira de analisar o envolvimento dos estudantes com as ciências (Duschl, 2008; Franco \& Munford, 2020; Jiménez-Aleixandre \& Crujeiras, 2017; Kelly, 2008; Kelly \& Licona, 2018). O ensino de ciências por meio das práticas surge como explicitação da compreensão da atividade científica como social e, em decorrência, como expectativa de possibilitar, aos estudantes, interações com diferentes domínios do conhecimento científico.

Tendo estas ideias como pressupostos iniciais, neste estudo, temos como objetivo analisar práticas realizadas por estudantes dos anos iniciais do Ensino Fundamental durante o planejamento de investigação de fenômenos da natureza. Também é nosso interesse discorrer sobre este processo na perspectiva das condições experimentais expostas ou construídas e que regulam o empreendimento epistêmico destes estudantes. 


\section{AS PRÁTICAS DAS CIÊNCIAS}

Para o estudo que aqui apresentamos, recorremos brevemente a concepções sobre a atividade científica trazida por antropólogos, filósofos e sociólogos da ciência. Julgamos interessante e oportuno adotar esta vertente, pois ela pode permitir a identificação e o reconhecimento de açóes que circundam a construção de conhecimento e a avaliação destes entendimentos.

Pesquisas realizadas com foco no trabalho de laboratório (Latour \& Woolgar, 1986; Pickering, 1995; Rheinberger, 1997) propõem a mutabilidade dos papéis de objetos e informaçóes na investigação. Em nossa interpretação, a transformação destes é parte integrante da construção de conhecimento; e, neste processo, os limites entre os aparatos tecnológicos, o contexto social e os arcabouços conceitual e epistêmico não são claramente identificados ou definidos, em um entrelaçamento que caracteriza esta construção e, em última análise, a atividade científica.

Rheinberger (1997) considera o papel da teoria na realização de experimentos e na construção de conhecimentos nas ciências. Para ele, o conceito deve ser analisado a partir de sua ambivalência: "ele é um produto da atividade cientifica e é um poderoso instrumento de execução da mesma atividade" (p. 13, tradução nossa). Adicionalmente a isso, Rheinberger (1997) discute que os estudos de história e filosofia da ciência, desde o início da década de 1980, passaram a entender o laboratório para além de uma mera situação ou evento em que acontece a verificação empírica de proposiçóes teóricas. A partir disso, discute o experimento pautado no "contexto da explicação" em oposição ao experimento no "contexto da descoberta". Em sua perspectiva, as ideias investigadas pela ciência são desenvolvidas na relação com conhecimentos da área. " $O$ corpo dinâmico de conhecimentos, a rede de práticas estruturada pelos laboratórios, instrumentos e arranjos experimentais são um processo de raciocínio em si” (p. 20, tradução nossa). A partir disso, ele defende que a intenção não é encontrar uma lógica que permita explicar relações entre teoria e experimento, mas analisar situaçóes experimentais. Para Rheinberger (1997), em uma situação experimental

irrevogavelmente local e situada no tempo e espaço, há objetos científicos e condiçôes técnicas para eles se tornarem presentes, há diversidade na reprodução de sistemas experimentais, há conjecturas destes sistemas e suas representaçôes. Tudo isso são noções relacionadas ao processo de produção, o que eu chamo de objetos epistêmicos (p. 21, tradução nossa).

Os objetos epistêmicos, segundo o autor, são os objetos da investigação e podem ser entidades materiais ou processos. Ele ainda expressa certa vagueza como característica dos objetos epistêmicos uma vez que eles estão envolvidos com coisas que ainda não são conhecidas. Em contraposição, os objetos técnicos ou condiçốes experimentais permitem que os objetos de investigação articulem com práticas epistêmicas e materiais culturais. Rheinberger (1997) também apresenta ideias que nos permitem conjecturar a respeito da mutabilidade entre objetos epistêmicos e condições experimentais, pois propóe que estas últimas "determinam o campo de possiveis representaçôes do objeto epistêmico; e objetos epistêmicos suficientemente estáveis tornam repertório técnico de um arranjo experimental" (p. 29, tradução nossa).

Rheinberger (1997) propõe estas ações como intercambiáveis. Os objetos epistêmicos são materiais ou processos que compóem e constituem os objetos de investigação, enquanto as condições experimentais (ou objetos técnicos) são elementos por meio dos quais os objetos de investigação são estabelecidos e articulados e determinam as possíveis representações dos objetos epistêmicos. Os estudos apresentados pelo autor sobre a experimentação nas ciências trazem nuances que aproximam e distanciam as técnicas e os passos metodológicos realizados como reprodução das açôes significativamente orquestradas para avaliar premissas e hipóteses. Chamadas de práticas, estas diversas açôes entrecruzam-se na construção de novos entendimentos sobre a situação em investigação. Rheinberger (1997) toma a experimentação, no campo da atividade científica, como um conjunto de práticas epistêmicas que caracteriza a cultura da ciência. Para ele, práticas e 
conceitos "vêm embalados juntos" (p. 28, tradução nossa) e, tomando isso como premissa, podemos inferir que aprender ciência é aprender conceitos e práticas.

Pickering (1995) trata da ciência como prática e cultura: enquanto a primeira é um campo de recursos em que o trabalho de um cientista é desenvolvido, a segunda se refere às açốes realizadas neste campo. Relacionadas a um campo de atuação, as práticas são, portanto, sociais e compõem a ciência. Ideia muito semelhante é discutida por Longino $(1990,2002)$ ao defender a ciência como um conhecimento social.

Podendo ser reconhecida como uma característica intrínseca à ciência, Longino (1990, 2002) avalia a objetividade como uma consequência de processos e práticas que envolvem a atividade de investigação da ciência. Para ela, a ciência é social e, portanto, suas práticas são sociais, o que a permite entender que a "prática cientifica é governada por normas e valores gerados do entendimento dos objetivos da investigação cientifica" (1990, p. 4, tradução nossa).

Em perspectiva semelhante, em livro que analisa como as ciências constroem conhecimento, Karin Knorr-Cetina (1999) investiga a atividade científica. Assim, para entender a cultura científica que, em sua percepção, é uma cultura epistêmica, pois se relaciona ao conhecimento, é preciso entender suas práticas, que são atos de construir e consolidar conhecimento.

\section{AS PRÁTICAS DAS CIÊNCIAS NO ENSINO DE CIÊNCIAS}

Pesquisas da área da Educação em Ciências têm conferido atenção a como práticas epistêmicas podem ser transpostas para a realidade escolar (Jiménez-Aleixandre \& Crujeiras, 2017; Kelly \& Licona, 2018; Sasseron \& Duschl, 2016; Silva, Gerolin \& Trivelato, 2018; Silva \& Mortimer, 2009).

$\mathrm{Na}$ relação com as ideias de Rheinberger (1997), podemos entender que atividades de ensino em que os estudantes executam açôes descritas em roteiros previamente organizados podem privilegiar o contato deles com condições experimentais, mas podem pouco contribuir para o envolvimento dos alunos com os objetos epistêmicos e a vivência com aspectos a eles relacionados, como, por exemplo, o raciocínio utilizado para compreender, avaliar e comunicar as ideias em construção.

O desenvolvimento de ações em que conceitos, processos e práticas podem ser trabalhados conjuntamente pode se relacionar a ideias que fundamentam as atividades descritas pelo ensino por investigação, ou seja, atividades em que os estudantes se engajam com a resolução de um problema, construindo planos de trabalho, coletando e analisando dados, identificando as variáveis relevantes e construindo modelos explicativos para as situaçôes investigadas (Carvalho, 2018; Sasseron, 2015).

Há muitas discussões sobre o que é o ensino por investigação e como ele pode ser implementado em sala de aula, surgindo interpretaçóes que permitem vislumbrar duas principais vertentes: uma delas associada à investigação como forma pela qual ocorre a abordagem de conteúdos e a outra vinculada à investigação como um objetivo da formação, pressupondo que modos de investigar são o conteúdo em foco. Estas duas principais concepções podem ser conferidas em estudos que analisam sua implementação em diferentes realidades (Abd-El-Khalick et al, 2004; Welch et al, 1981).

Concordando com a caracterização do ensino por investigação como forma de ensinar e como objetivo do ensino, entendemos que ele pode ser compreendido como abordagem didática (Sasseron, 2015), conferindo aos professores o papel de promover interaçóes dos estudantes com os fenômenos, os fatos e as informaçóes e, com isso, permitir que investigações sejam concretizadas pelos alunos. Deste modo, o planejamento e a implementação das atividades requerem ações contínuas dos professores para fomentar o envolvimento dos estudantes na participação em atividades de investigação, de argumentação e de construção de modelos explicativos como circunstâncias propositivas e avaliativas pautadas em análise crítica, em que as discussões tragam coesão e coerência para o entendimento elaborado (Silva, Gerolin \& Trivelato, 2018; Silva \& Silva, 2019). 
Em recente análise dos fundamentos teóricos e metodológicos do ensino por investigação, Carvalho (2018) o apresenta como as situaçóes em que professores abordam conteúdos conceituais criando oportunidades para os estudantes: "pensarem, levando em conta a estrutura do conbecimento; falarem, evidenciando seus argumentos e conhecimentos construidos; lerem, entendendo criticamente o conteúdo lido; escreverem, mostrando autoria e clareza nas ideias expostas” (p. 766). Esta descrição sobre as condiçôes para a promoção do ensino por investigação permite encontrar relação com as dimensóes conceitual, social e epistêmica do conhecimento tratadas por Duschl (2008) como necessários para a constituição de oportunidade em aulas de ciências para a formação do sujeito contemporâneo. E, de modo integrado, trazendo também a dimensão material do conhecimento, conforme proposta por Stroupe (2014).

Para avançar nesta discussão, parece-nos importante analisar as práticas epistêmicas no ensino de ciências. Diversas pesquisas já foram realizadas com este intuito e elas revelam esforços para definir o que são práticas epistêmicas (Jiménez-Aleixandre \& Crujeiras; Jiménez-Aleixandre et al, 2008; Kelly, 2008; Kelly \& Duschl, 2002; Kelly \& Licona, 2018, 2017), para estudar como elas surgem nas interaçóes discursivas em aula entre professor e alunos (Ferraz \& Sasseron, 2017; Lidar, Lundqvist \& Ostman, 2005; Silva, 2015) e em diferentes tarefas de sala de aula (Manzoni-de-Almeida, Marzin-Janvier \& Trivelato, 2016; Sasseron \& Duschl, 2016; Silva, Gerolin \& Trivelato, 2018).

Começamos por expor o entendimento de que as práticas epistêmicas se relacionam aos movimentos de compreensão das razões por meio das quais se sabe algo e pelas quais é possível referendar um conhecimento. Em Kelly e Licona (2018), elas são apresentadas como "formas socialmente organizadas e interativamente realizadas” (p. 140, tradução nossa) para propor, comunicar, avaliar e legitimar conhecimentos. Os autores ainda as caracterizam como sendo interativas, contextualizadas, intertextuais e consequenciais. Assim, por serem interativas e contextualizadas, elas são sociais, imersas e circunscritas em práticas sociais e normas culturais, que, no discurso, revelam a intertextualidade e referendam consequências, pelo conhecimento legitimado.

As características mencionadas permitem afirmar que as práticas epistêmicas não são exclusivas a um campo de conhecimento, embora existam práticas que caracterizam o empreendimento de construção de entendimento sobre fenômenos para cada área. Na relação com estas ideias, Jiménez-Aleixandre e Crujeiras (2017) propóem que o ensino pautado nas práticas epistêmicas deve considerar as especificidades das áreas de conhecimento. Para as autoras, a abordagem de questóes de ordem epistêmica, e portanto social, pode se concretizar em aulas de ciências pela investigação, pela argumentação e pela modelagem; sendo que a investigação se concentra em torno de problemas, deflagrando situações em que ocorrem o planejamento para a investigação, a constituição de perguntas, a observação e a experimentação e a obtenção de dados; a modelagem circunda o fenômeno, com processos imaginativos para consolidação de hipóteses e a predição de ocorrências e decorrências para que seja possível a construção de teorias e modelos; e a argumentação centrada nas evidências e alegações, com processos de interrogação e de crítica que permitam a coordenação entre evidências e alegaçóes.

É importante afirmar ainda, considerando os pressupostos sobre o ensino por investigação já expostos, que a consolidação da investigação em sala de aula se relaciona ao trabalho simultâneo de modelagem e de argumentação; pois para colocar uma investigação em curso é necessário argumentar com os pares para construir e executar planos de ações, analisar dados e construir modelos explicativos; de mesmo modo, é preciso argumentar pelas propostas e investigar contextos, situações e informaçôes para propor modelos explicativos, possibilitando a predição de fatos. Assim planejadas, investigação, modelagem e argumentação necessitam do empreendimento de práticas epistêmicas de proposição, comunicação, avaliação e legitimação.

As ideias discutidas expõem nossa percepção de que as práticas epistêmicas não são ensinadas por meio de simples apresentação do que sejam: elas devem ser vivenciadas, experimentadas, uma vez que demandam o envolvimento com conhecimentos, com um grupo e com as normas e padrôes que conectam pessoas e conhecimentos; devem surgir pelas oportunidades conferidas para que os estudantes proponham, comuniquem, avaliem e legitimem ideias e conhecimentos em atividades didáticas. 
Parece claro também que, em situações de ensino, a depender das estratégias didático-pedagógicas em uso, as práticas epistêmicas têm mais ou menos possibilidade de serem desenvolvidas pelos estudantes. Mas sendo interativas e contextualizadas, não é esperado que sejam trabalhadas em situações em que o empreendimento seja privado (Stroupe, 2014), revelando a necessidade de que o conhecimento seja trabalhado socialmente. De modo semelhante, por serem intertextuais e consequenciais, surgem em cenários em que o discurso, seus símbolos e signos, são comunicados e compartilhados gerando possibilidade de validação pelo grupo, ao mesmo tempo em que cria movimentos de empoderamento e de enculturação.

\section{ASPECTOS METODOLÓGICOS DESTE ESTUDO}

Conforme apresentado na introdução, o objetivo deste estudo é analisar como estudantes dos anos iniciais do Ensino Fundamental estruturam práticas para o planejamento de investigação de problema envolvendo fenômenos do mundo natural.

As discussões teóricas até aqui tecidas permitem avaliar as práticas epistêmicas como elemento do ensino de ciências na perspectiva da investigação que possibilita o contato com as dimensóes conceitual, social, epistêmica e material do conhecimento. Para dar prosseguimento a esta discussão, apresentaremos exemplos de discussóes ocorridas em sala de aula com o intuito de analisar o desenvolvimento destas práticas entre estudantes que realizam investigaçôes sobre temas das ciências.

Porque nossa intenção é exemplificar como os estudantes constroem e realizam uma investigação, optamos por uma análise qualitativa entendendo que, deste modo, será possível “identificar as nuances do entendimento subjetivo que motiva os vários participantes" (Erickson, 1998, p. 1155, tradução nossa), ou seja, poderemos encontrar aspectos sobre como a investigação é planejada e executada. E porque o presente trabalho analisa situações ocorridas com uma única turma, é um estudo de caso (Lüdke \& André, 1986), representando esta situação específica, em um dado contexto, com objetivos delimitados a fim de que a atenção não seja convergida para aspectos que, mesmo interessantes, não condizem com nossas preocupações.

\section{A situação de ensino e as informações em análise}

Para a análise que apresentamos a seguir, acompanhamos e gravamos em áudio e vídeo interações ocorridas em situações de oficinas frequentadas por estudantes dos anos iniciais do Ensino Fundamental de uma escola pública estadual. À época das gravações, no segundo semestre de 2018, os estudantes tinham idades entre 7 e 11 anos.

Nesta escola, em todos os semestres são oferecidas oficinas aos estudantes. A participação é obrigatória, mas é possível escolher aquela que o estudante deseja participar a partir da lista dos temas e das ementas. Os temas são variados e seu oferecimento conta com a participação de toda a comunidade escolar: professores, auxiliares de ensino, pais e responsáveis, egressos da escola e estudantes de graduação e de pós-graduação que têm relação com a mesma. Cada oficina tem seis encontros de uma hora cada, e os encontros acontecem uma vez por semana. Entre setembro e novembro de 2018, foi oferecida a oficina "Investigação Científica na Escola”. Onze estudantes participaram desta oficina oferecida por alunos de graduação e de pós-graduação de licenciaturas e programas de pós-graduação vinculados ao ensino de ciências, que serão chamados, neste trabalho, de monitores ${ }^{2}$. Os onze estudantes participantes da oficina estavam em anos escolares diferentes, embora tivessem contato em outras atividades já realizadas na escola. Este grupo tinha 4 estudantes do 1o ano, 2 estudantes do 2o ano, 1 do 3o ano, 3 alunos do 4o ano e 1 estudante do 5o ano.

Para a gravação dos encontros e uso do material para finalidades de pesquisa, os estudantes receberam um TCLE (termo de consentimento livre e esclarecido) que foi entregue a seus pais e responsáveis para assinatura. Apenas os estudantes cujos pais assinaram o TCLE estão apresentados nas discussões trazidas neste texto. Todos eles tiveram seus nomes alterados para preservar a identidade. 
A oficina "Investigação Científica na Escola" foi planejada para que os estudantes se envolvessem nas diferentes etapas de uma investigação, desde a elaboração do tema a ser investigado, passando pelas atividades de exploração do texto e culminando com a apresentação dos resultados finais ao grupo.

Assim, no primeiro encontro, os estudantes souberam que era preciso definir um tema para se pesquisar. Considerando o número de estudantes, foram formados três grupos para os trabalhos de investigação. Ficou definido que os grupos estudariam (1) Como se formam tempestades; (2) Como saber a idade de uma árvore; e (3) Existência de vida no rio que margeia a escola.

Os quatro encontros seguintes foram destinados à investigação, cada qual seguindo novos objetivos e ações traçados pelos estudantes com a orientação dos monitores para que o tema escolhido pudesse ser estudado. Estes quatro encontros podem ser entendidos como compostos de dois principais momentos: o primeiro deles sendo as discussões sobre conhecimentos que os alunos já tinham e a sistematização de novas informaçóes a partir de experimentações realizadas ao longo da semana, e o segundo momento voltado à preparação para uma nova experimentação a ser acompanhada pelos alunos ao longo da semana entre um encontro e outro. Isso permitiu que as grandes práticas epistêmicas pudessem ter cenário para seu desenvolvimento, uma vez que a comunicação levava à proposição, avaliação e legitimação de ideias e conhecimentos pelo grupo, bem como à proposição de modos de experimentação de novos problemas, cujo dados eram depois comunicados e avaliados e os conhecimentos legitimados.

O sexto e último dia de oficina foi a apresentação dos resultados de cada grupo para os demais colegas, como um momento de comunicar processos e produtos realizados e construídos em cada investigação.

Embora diferentes entre si, na relação com o conteúdo a ser explorado, ao longo das reunióes de planejamento para cada oficina, eram discutidos os problemas e as experimentaçóes que estavam sendo realizadas por cada grupo e, com isso, os monitores se preparavam para abordar e mobilizar com os estudantes as dimensóes conceitual, social e epistêmica dos conhecimentos científicos (Duschl, 2008), bem como à dimensão material, adicionada por Stroupe (2014) como importante para o desenvolvimento de atividades em aulas de ciências. Sempre atentos para que as investigaçóes fossem realizadas a partir das propostas dos estudantes, nestas reunióes, os monitores discutiam como explorar as ideias levantadas no encontro anterior. Era uma forma também de se preparar, levando para a oficina, materiais que poderiam ajudar os estudantes a concretizarem, em experimentos, as ideias levantadas. Assim, o papel dos monitores era de encontrar meios para oferecer condições para a investigação.

Cada qual realizando investigaçôes a seu modo, é possível afirmar que os resultados do envolvimento dos estudantes são semelhantes em todos os grupos. Para este trabalho, devido à qualidade sonora das gravaçôes, escolhemos por analisar as discussões ocorridas no grupo da temática (2), que será sucintamente designado como grupo Árvore.

O grupo Árvore era formado por quatro estudantes, coincidentemente todas meninas, sendo que duas delas (Celina e Laura ${ }^{3}$ ) estavam no 1o ano do Ensino Fundamental, uma (Janaína) no 3o ano e a quarta participante era aluna (Marta) do $4^{0}$ ano. Havia dois monitores neste grupo e, à época da coleta, ele era estudante de Licenciatura em Física e ela, licenciada em Biologia e doutoranda em Educação. A investigação deste grupo girava em torno da pergunta "Como saber a idade de uma árvore?".

A análise qualitativa realizada será apresentada neste texto a partir da descrição de dois encontros da oficina, em que a fonte das informaçốes são as gravaçôes em áudio e vídeo das interaçôes ocorridas nestes momentos, havendo incursóes de análise a partir dos referenciais teóricos mencionados ao longo deste manuscrito.

Em outros trabalhos de nosso grupo de pesquisa, temos nos pautado na transcrição de falas como uma forma por meio da qual conseguimos acompanhar as interaçóes discursivas ocorridas em uma situação didática (Carvalho, 2004; Nascimento \& Sasseron, 2019; Sasseron, 2020, 2015) e, com isso, acompanhar como ocorrem estas interaçôes e os processos para construção de entendimento sobre os temas em discussão nas aulas. 
Transcrevemos as falas na íntegra e as organizamos em quadros em que cada linha é um turno de fala. Seguindo indicaçóes para as transcrições de gravaçôes sugeridas por Carvalho (2006), adotamos como turno de fala a explicitação da fala de um sujeito, independentemente da duração da mesma; identificamos entre parênteses as ações realizadas pelos sujeitos durante a fala; usamos o símbolo (...) para representar pausa momentânea e as reticências para designar situações em que uma fala ou mesmo uma palavra não foi completada.

\section{ANALISANDO O DESENVOLVIMENTO DE PRÁTICAS EM UMA SITUAÇÃO DE INVESTIGAÇÃO}

Devido à natureza da oficina, em que os problemas são apresentados pelos estudantes e investigados por eles mesmos, os monitores os auxiliaram a refinar o problema e a encontrar modos de trabalho para que observaçóes pudessem ser feitas e analisadas. Nesta análise, focamos no planejamento da investigação sobre a observação do desenvolvimento de uma planta. Esta investigação surgiu após as estudantes terem discutido entre si e com os monitores o que caracteriza um ser vivo e, com isso, as estudantes buscaram analisar se uma planta cresce. No encontro analisado, estavam presentes Celina, Laura e Marta, além dos dois monitores.

Com o objetivo de avaliar o envolvimento das estudantes com o trabalho realizado, analisamos suas atividades considerando menções a elementos da investigação: (a) materiais para concretização do experimento, (b) construção de arranjo experimental e (c) formas de obtenção e de registro dos dados. Entendemos que estes elementos representam organização de ideias e construção de práticas que podem ser associados aos objetos epistêmicos ou às condiçóes experimentais (Rheinberger, 1997).

Para que o envolvimento com as práticas epistêmicas possa ser analisado, nas discussóes ocorridas ao longo de todo o processo, buscaremos também encontrar evidências de processos para propor, comunicar, avaliar e legitimar conhecimentos (Kelly \& Licona, 2018).

Considerando os aportes teóricos acima mencionados, procedemos à leitura das transcriçốes de modo a buscar evidências de ocorrência de elementos da investigação e das práticas epistêmicas. Isso permitiu categorizar episódios de discussão ou turnos de fala. Para garantir confiabilidade às categorizaçôes realizadas, procedemos a discussóes sobre elas no grupo de pesquisa. Nestes instantes, ocorreram debates que permitiram referendar o proposto ou rever categorizaçôes garantindo a qualidade do processo.

Na apresentação da análise, exibimos a transcrição de discussões ocorridas ao longo do encontro e, na sequência, discutimos as evidências encontradas para a categorização de episódios ou turnos considerando os elementos da investigação realizados e as práticas epistêmicas manifestadas. Este procedimento foi adotado por dois motivos: possibilitar a exposição mais cuidadosa de evidências que sustentam a categorização realizada e organizar cronologicamente a discussão, excluindo trechos de fala em que as conversas não estavam direcionadas ao tema central da investigação (como, por exemplo, situações em que as estudantes conversam sobre seus materiais escolares e sobre atividades de sua rotina não vinculadas ao tema da oficina).

\section{A investigação: Planta cresce?}

O encontro tem início com estudantes e monitores discutindo características que permitem identificar um ser vivo e algo não vivo. Não há questionamento pelos monitores da diferença entre vivo e morto e ser vivo e objetos inanimados. Entendemos que isso não ocorreu por não ser o foco da atividade. O objetivo principal era permitir que as estudantes planejassem modos de acompanhar o crescimento de uma planta, o que persistirá ao longo da discussão apresentada nas figuras 1 e 2. 
Figura 1. Quadro de transcrição de falas 1

\begin{tabular}{|c|l|l|}
\hline Linha & Falante & \multicolumn{1}{c|}{ Fala } \\
\hline 1 & Monitora & $\begin{array}{l}\text { Certo. Ela cresceu de novo. Como a gente pode provar, a gente aqui, que uma planta tá } \\
\text { viva? O que que a gente pode fazer? }\end{array}$ \\
\hline 2 & Marta & Eu sei. A planta, ela. A gente pode observar uma planta crescer. \\
\hline 3 & Monitor & Ah! \\
\hline 4 & Monitora & (bate palma concordando) Vocês ouviram o que a Marta falou? \\
\hline 5 & Marta & Morto não cresce, agora o que é vivo cresce. \\
\hline 6 & Monitora & $\begin{array}{l}\text { Então deixa eu anotar aqui. (vai para a lousa) A Marta falou que a gente pode observar (...) } \\
\text { uma planta (...) }\end{array}$ \\
\hline 7 & Monitor & Crescer. \\
\hline 8 & Monitora & Crescer. Fala, Laura. Laura, não, desculpa, Celina. \\
\hline
\end{tabular}

Nestes turnos de fala, as estudantes, a partir de interaçóes com os monitores, começam a propor açóes como forma de obtenção e de registro dos dados. Há, inclusive, na linha 5, uma justificativa trazida por manter para referendar o plano por ela proposto. A partir da discussão, pode-se inferir que Marta entende que, como um ser morto não cresce, uma evidência para referendar que uma planta está viva pode ser obtida por meio do acompanhamento de seu crescimento.

Surge, então, a necessidade de encontrar mecanismos para este acompanhamento.

Figura 2. Quadro de transcrição de falas 2

\begin{tabular}{|c|c|l|}
\hline Linha & Falante & \multicolumn{1}{|c|}{ Fala } \\
\hline 1 & Celina & A gente pode colocar um óculos. \\
\hline 2 & Monitora & Colocar o quê? \\
\hline 3 & Celina & Um óculos. \\
\hline 4 & Monitora & Colocar um óculos? \\
\hline 5 & Celina & É. \\
\hline 6 & Monitora & Para ver a planta crescendo? \\
\hline 7 & Celina & É. \\
\hline 8 & Monitora & Tipo alguma coisa para poder aumentar? \\
\hline 9 & Celina & É. \\
\hline 10 & Monitora & Podemos aumen... Usar alguma coisa para poder aumentar a planta. \\
\hline 11 & Marta & Uma lupa. Ou um microscópio. Eu já vi uma planta no microscópio. \\
\hline
\end{tabular}

Ao longo das interações destacadas no Quadro de interaçóes 2, podemos perceber que as estudantes buscam um artefato que permita acompanhar o crescimento da planta. Não sabemos se Celina esqueceu o nome "lupa" e, com isso, a chama de "óculos", mas pelas interações com a monitora, é possível perceber que ela sabe o tipo de objeto necessário para a observação: algo que possa aumentar o tamanho do objeto em análise; o que é nomeado por Marta na linha 11. Esta discussão revela atenção para as formas de obtenção e de registro dos dados havendo a proposição, pelas alunas, sobre as condiçóes experimentais para isso acontecer.

Tendo sido discutido pelas estudantes a partir das interaçóes com os monitores que é preciso acompanhar o crescimento de uma planta para saber se ela é um ser vivo, tem início uma discussão sobre como é possível fazer uma planta crescer, conforme exposto na figura 3. 
Figura 3. Quadro de transcrição de falas 3

\begin{tabular}{|c|c|c|}
\hline Linha & Falante & Fala \\
\hline 1 & Monitora & Como que a gente faz para a planta crescer? Laura. Opa, não! Celina. Desculpa. Celina. \\
\hline 2 & Celina & $\begin{array}{l}\text { Ir na horta, pegar alguma coisa que planta de lá, aí colocar um vaso com terra, colocar ela } \\
\text { num vaso com terra, aí colocar água e espera ela crescer, aí coloca mais água e espera ela } \\
\text { crescer, aí coloca mais água e espera ela crescer, aí coloca mais água e espera ela crescer. }\end{array}$ \\
\hline 3 & Marta & Não é só água que faz ela crescer. \\
\hline 4 & Monitora & Então, mas aí já... \\
\hline 5 & Celina & (fala inaudível) \\
\hline 6 & Monitora & $\begin{array}{l}\text { Tá bom, então pera lá, vamos recordar o que foi que a Celina falou: a gente pode ir na horta, } \\
\text { pegar uma planta, plantar num vasinho com terra, colocar água. }\end{array}$ \\
\hline 7 & Celina & Mas tem que ser com a raiz. \\
\hline 8 & Monitora & Ah! Pegar uma plantinha com raiz. Tá, não esquece o que foi que a Celina falou. \\
\hline 9 & & (conversas indistintas) \\
\hline 10 & Monitora & Você viu que uma planta murcha e morre? Por que será que ela murcha? \\
\hline 11 & Marta & Porque ela tá morrendo. \\
\hline 12 & Monitora & Porque ela tá morrendo? E como é que a gente pode fazer para evitar que ela morra. \\
\hline 13 & Marta & É só a gente cuidar dela. E eu sei as coisas que precisa. Precisa de água, sol, terra e... \\
\hline 14 & Celina & E terra. \\
\hline 15 & Marta & E terra. A gente precisa de água, sol, terra e adubo. \\
\hline 16 & Celina & Porque a gente precisa... \\
\hline 17 & Monitor & E a planta? \\
\hline 18 & Monitora & (anotando na lousa) água, sol... \\
\hline 19 & Monitor & E se a gente não tiver a planta? \\
\hline 20 & Celina & Porque às vezes precisa trocar de terra. \\
\hline 21 & Monitora & $\begin{array}{l}\text { Olha, calma, vamos aqui rapidinho recapitular. (fala desconsiderada por refrasear ideia } \\
\text { trazida por aluna cujos pais e responsáveis não assinaram o TCLE) Aí eu perguntei "por que } \\
\text { será que isso acontece?", aí a Marta disse: "Ah, eu sei, porque uma planta precisa de água, } \\
\text { de sol, terra e da planta". }\end{array}$ \\
\hline 22 & Monitor & E da própria planta. Mas não tem jeito de arranjar uma planta sem ter outra planta? \\
\hline 23 & Monitora & $\begin{array}{l}\text { Porque a Celina falou assim: "Ó, não esqueça de arrancar a planta com a raiz." E se a gente } \\
\text { não tiver uma planta já com a raiz? Como é que a gente pode... }\end{array}$ \\
\hline 24 & Marta & A gente pode pegar uma semente. \\
\hline 25 & Monitora & Ah! \\
\hline 26 & Monitor & Ah! Então não precisa da planta. \\
\hline 27 & Monitora & Então precisa de quê? \\
\hline 28 & Marta & Da semente. \\
\hline 29 & Monitora & Da semente, né? \\
\hline 30 & Celina & Sim. \\
\hline
\end{tabular}

Diante do problema de acompanhar o crescimento de uma planta, as estudantes lembram os elementos necessários para o bom desenvolvimento: necessidade de água, luz solar, terra e adubo.

Neste trecho, percebemos que as alunas discutem sobre materiais para concretização do experimento e sobre a construção de arranjo experimental sendo que os materiais são apresentados como condições experimentais que devem ser considerados durante os testes. As proposições das alunas revelam avaliação destas condiçôes com base em experiências prévias como, por exemplo, a importância de se, ao 
transpor uma planta para outro recipiente, cuidar de sua raiz para que ela não murche ou morra. Nestes trechos de discussão, percebemos também a legitimação das ideias em discussão, pois o que é proposto por uma estudante é referendado pela outra.

Em seguida, na discussão apresentada na figura 4, os monitores propóem o plantio de sementes.

Figura 4. Quadro de transcrição de falas 4

\begin{tabular}{|c|c|l|}
\hline Linha & Falante & \multicolumn{1}{|c|}{ Fala } \\
\hline 1 & Monitora & Legal! E o que que é que vocês acham da gente fazer uma planta nascer? \\
\hline 2 & Celina & (levantando-se da carteira) Sim. Agora! \\
\hline 3 & Marta & (levantando-se da carteira) Mas a gente vai fazer agora? \\
\hline 4 & Monitor & Mas vai dar tempo de crescer agora? \\
\hline 5 & Marta & Não. Vai demorar anos. \\
\hline 6 & Celina & Sim, a gente... \\
\hline 7 & Monitora & Anos? Vai demorar para crescer? \\
\hline 8 & Marta & Vai demorar meses. \\
\hline 9 & Celina & $\begin{array}{l}\text { A gente pode fazer (inaudível) e faz ela viver, aí ela vai nascer até chegar no teto, aí ela vai } \\
\text { diminuir, aí a gente vai deixar ela crescer de novo, até ela diminuir, aí a gente faz tudo de } \\
\text { novo. }\end{array}$ \\
\hline 10 & Marta & É. A gente pode usar alguma coisa para ele crescer. Por exemplo, adubo. \\
\hline 11 & Monitor & Ah! Então dá para usar adubo também. \\
\hline 12 & Monitora & (na lousa) Então vou pôr aqui que também precisa de adubo, né? \\
\hline 13 & Celina & Sim. \\
\hline 14 & Monitor & Nossa! Quanta coisa precisa para uma planta, né? \\
\hline & &
\end{tabular}

As alunas ficam animadas com a possibilidade de plantarem sementes e os monitores perguntam se isso não demoraria muito tempo para obterem o resultado. Celina parece muito engajada com a tarefa detalhando o que imagina que vá observar, embora não exponha ideias sobre como executá-la. Marta sugere usar adubo para a planta crescer mais e, possivelmente, mais rápido. Percebemos que novamente a discussão é sobre materiais para concretização do experimento, mas é interessante notar agora que Marta destaca um destes materiais, o adubo. Isso revela mais uma vez que as ideias propostas em discussões anteriores (especialmente na linha 15 do quadro de interaçôes 3) foram legitimadas e este artefato é introduzido como potencializador do efeito, o que nos permite entender a percepção de Marta sobre o adubo como um objeto epistêmico, porque poderia ser analisado qual o impacto do seu uso para o desenvolvimento da planta.

Em face de tal discussão, os monitores distribuem para as alunas grãos de feijão e de milho e pedem que as alunas plantem as sementes para trazerem no próximo encontro, em uma semana. Seguem a isso, as interaçóes apresentadas na figura 5 , em que as alunas expóem preocupaçóes com o plantio.

Figura 5. Quadro de transcrição de falas 5

\begin{tabular}{|c|c|l|}
\hline Linha & Falante & \multicolumn{1}{c|}{ Fala } \\
\hline 1 & Celina & Eu não posso, porque eu tenho gata e minha gata detona planta. \\
\hline 2 & Monitora & Tem que tomar cuidado. \\
\hline 3 & Marta & $\begin{array}{l}\text { Eu já sei. Eu vou pedir um vasinho para a mamãe e aí eu vou deixar ela no quarto porque } \\
\text { pega sol. }\end{array}$ \\
\hline 4 & Celina & Eu não tenho vaso. \\
\hline 5 & Marta & E aí eu deixo lá e eu não esqueço de regar porque sempre que eu acordo eu vou ver a planta. \\
\hline
\end{tabular}


Percebemos que as estudantes comunicam ideias sobre a construção do arranjo experimental pela preocupação de Celina com o seu gato que tem hábito de atacar outras plantas da casa e propõem ações necessárias para a atividade, representadas pelo cuidado destacado por Marta ao lembrar de local em sua casa em que há luz solar incidindo diretamente e que, portanto, seria adequado para manter o vaso com as sementes plantadas. Estes elementos permitem identificar que o arranjo experimental em elaboração é aqui tomado como uma condição experimental, pois elas não demonstram preocupação em analisar estes aspectos, apenas registrando-os como contexto.

Tendo as estudantes exposto estas condições, os monitores frisam que o importante é fazer a planta nascer, mas não oferecem diretrizes sobre como fazê-lo, mencionando que isso é uma decisão de cada uma.

Em seguida, os monitores entregam blocos de anotaçóes para as estudantes e pedem para que, além de trazerem as plantas para a sala de aula na semana seguinte, façam registros ao longo da semana sobre o desenvolvimento das sementes. Nas figuras 6 e 7, as estudantes discutem modos para a realização dos registros.

Figura 6. Quadro de transcrição de falas 6

\begin{tabular}{|c|c|l|}
\hline Linha & Falante & \multicolumn{1}{|c|}{ Fala } \\
\hline 1 & Marta & A gente pode tirar foto. \\
\hline 2 & Monitora & Olha! É uma opção legal. Será que é legal tirar foto? \\
\hline 3 & Celina & (falando diretamente com a monitora) Eu consigo tirar uma foto sua. \\
\hline 4 & Monitora & Tirar foto quando? Em que momento? Todo dia, toda hora? Que hora? \\
\hline 5 & Marta & Todo dia de manhã, de tarde e de noite. \\
\hline 6 & Monitora & Ah, que legal. \\
\hline 7 & Celina & De tarde não dá, gente. \\
\hline 8 & Monitora & De tarde não dá. Por que que não dá? \\
\hline 9 & Celina & Porque a gente estuda. \\
\hline 10 & Vários & Conversas indistintas sobre a coleta de informações por meio de fotografias. \\
\hline 11 & Monitor & Tá, mas e se eu não quiser tirar foto? A gente pode fazer mais alguma coisa? \\
\hline 12 & Marta & A gente pode anotar aqui no bloquinho. \\
\hline 13 & Monitor & Perfeito. \\
\hline 14 & Celina & Pode desenhar o desenho da planta. \\
\hline
\end{tabular}

A primeira ideia trazida pelas estudantes é a captura de imagens por fotografias. A opção de Marta seria por tirar fotos todos os dias pela manhã, à tarde e à noite, e Celina lembra que à tarde não é possível, uma vez que é o horário em que estão na escola. Ao longo da discussão, surge a ideia de haver anotação de cada um dos dias, caso não seja possível tirar fotos.

Nas discussões expostas nas figuras 6, identificamos que as discussões entre as estudantes e os monitores se pautam nas formas de registro de dados sobre o desenvolvimento das sementes que serão plantadas: registro por fotos ou escrita e desenho. Esta discussão revela características de objetos epistêmicos atribuídas ao registro, pois as próprias formas propostas para a coleta são colocadas em avaliação considerando a pertinência do formato e a possibilidade de coleta de dados por meio das formas sugeridas. Além disso, percebemos que, influenciadas pela demanda trazida pelos monitores, as alunas preocupam-se com a comunicação que poderá ser realizada a partir da obtenção e do registro dos dados. 


\section{DISCUSSÃO DOS RESULTADOS}

Destacamos aqui não buscar relações entre as práticas epistêmicas identificadas e os elementos da investigação, representados pelos (a) materiais para concretização do experimento, pela (b) construção de arranjo experimental e pelas (c) formas de obtenção e de registro dos dados. Isso pode ser importante em um estudo em que a análise seja voltada a um conjunto mais extenso de dados. Como já expusemos, o objetivo deste estudo é analisar práticas realizadas por estudantes dos anos iniciais do Ensino Fundamental durante o planejamento de investigação de fenômenos da natureza. Para isso, torna necessário entender como as condições experimentais expostas ou construídas regem e organizam o empreendimento epistêmico destes estudantes.

Importante pontuar que a análise exibida revela situaçóes em que as estudantes lidam tanto com objetos epistêmicos quanto com condiçóes experimentais. Esse fato evidencia que o planejamento da investigação é uma atividade complexa em que não apenas se define o que será investigado, mas também como isso será feito. Estes dois processos concatenados permitem o envolvimento das estudantes em sala de aula com as diferentes dimensões do conhecimento (Duschl, 2008, Stroupe, 2014), pois o foco não são apenas os conceitos e os processos de investigação, o que possibilitaria o contato com as dimensões conceitual e epistêmicas, mas também os modos que permitem propor e realizar os processos, ou seja, as dimensóes social e material do conhecimento.

Relembramos que o planejamento da oficina e a atuação dos monitores ao longo das atividades, como qualquer planejamento e intervenção didáticos, influenciaram diretamente no envolvimento das estudantes com a investigação, reforçando o caráter do ensino por investigação como abordagem didática (Sasseron, 2015). Isso porque os monitores auxiliaram ou instigaram processos de proposição de ideias, de comunicação de informações obtidos, de legitimação de conhecimentos e de avaliação das situações.

Importante destacar também que as práticas epistêmicas para propor, comunicar e avaliar informaçóes parecem ter sido decisivas para a transformação de uma condição experimental em um objeto epistêmico e vice-versa.

Outro interessante resultado que podemos evidenciar por esta análise diz respeito à manifestação das práticas epistêmicas com as características propostas, teoricamente, por Kelly e Licona (2018): serem interacionais, contextualizadas, intertextuais e consequenciais.

Percebemos marcas de que as práticas epistêmicas foram contextualizadas e interacionais porque todas as discussões ocorreram no coletivo, revelando a socialização para o acordo de ações como característica da investigação. Por isso também, havia normas acordadas no grupo e seguidas pelas estudantes como, por exemplo, a realização das tarefas conforme o proposto.

A característica de consequência entre as práticas epistêmicas fica clara logo no início das interações discursivas trazidas para a análise neste estudo, quando conhecimentos que as alunas já possuíam sobre elementos necessários para o plantio são retomados com a ajuda dos monitores e, assim, legitimados no grupo, permitindo proposiçôes para a construção de arranjo experimental com o qual seja possível acompanhar o desenvolvimento de uma planta.

A intertextualidade entre as práticas pode ser percebida em diferentes momentos das discussóes. Ressaltamos aqui, como exemplo de intertextualidade das práticas, a lembrança de Marta à necessidade de que a planta receba luz solar, algo mencionado na discussão da figura 3, na linha 13 , e retomado em sua fala na linha 3 da figura 5 ao apresentar como procederia para cultivar as sementes recebidas.

Outra importante observação advinda destes episódios de investigação está relacionada às características epistêmicas dos conhecimentos em construção. Segundo Windschitl, Thompson e Braaten (2008), em atividades investigativas em sala de aula, cinco características epistêmicas do conhecimento científico podem ser consideradas para tornar autêntico o trabalho com as práticas. Neste sentido, segundo os autores, é importante ter em conta se o conhecimento em investigação é testável, revisável, explicativo, conjectural e gerador.

Pudemos notar que os conhecimentos sobre os elementos necessários para o desenvolvimento de uma 
planta, legitimados pelo grupo no início da discussão da primeira investigação, foram geradores e conjecturais das novas investigaçôes apresentadas ao longo das discussóes. Ao mesmo tempo, pela influência dos monitores, as ideias das alunas foram consideradas para os testes. Os resultados destes estudos foram trazidos para a discussão no encontro seguinte, não analisado neste manuscrito. Neste processo, podem surgir oportunidades para a revisão de ideias como quando as estudantes consideram diferentes modos para registrar o desenvolvimento do experimento ao longo da semana. Além disso, as açốes planejadas são discutidas em grupo e, em alguns momentos, explicaçôes são fornecidas pelas estudantes sobre o porquê de realizar uma ação específica.

É importante destacar, uma vez mais, que as investigaçôes que ocorreram ao longo de todo o processo detalhado na seção anterior têm forte relação com a constituição de um espaço de interaçôes entre monitores e estudantes, pautada na distribuição de autoridade epistêmica às estudantes. Esta característica marcante das interaçôes permitiu a consolidação do empreendimento investigativo como algo público, social, coletivo.

\section{CONSIDERAÇÕES FINAIS}

Neste trabalho analisamos qualitativamente as investigações propostas por alunos do Ensino Fundamental a partir de apoios teóricos advindos da Antropologia e da Sociologia das Ciências e do campo da Educação em Ciências.

Diante do que expusemos até o momento, do ponto de vista teórico e empírico, podemos afirmar que a situação analisada revela investigações em situações de ensino com envolvimento epistêmico dos participantes.

Obviamente, é possível avaliar que as condições para as interações entre monitores e estudantes são bastante diferentes daquelas que encontramos em salas de aula regulares. Reconhecemos que o contexto em que as gravaçóes ocorreram e, portanto, que permitiu a organização dos dados expostos, foi, ao mesmo tempo, a possibilidade de a pesquisa se concretizar e sua limitação. Se a concretização de uma oficina, com pequeno grupo, permitiu que explorássemos um tema advindo do interesse dos estudantes, ficamos fadados a contar com um número bastante restrito de participantes pela estrutura da atividade.

Não é nosso intuito neste trabalho propor indicações de como isso pode ser transposto para outros contextos de educação formal, mas chamar a atenção para a possibilidade real de envolver alunos dos anos iniciais do Ensino Fundamental em investigaçôes em que as dimensóes social, conceitual, material e epistêmica são igualmente tratadas e analisadas. Além disso, diante dos resultados obtidos, o estudo também traz contribuições para o grupo de pesquisa a partir do entendimento da necessidade de estudar situaçóes semelhantes com um maior número de sujeitos envolvidos para o planejamento e execução de uma investigação.

Considerando a análise de situações de ensino conseguimos identificar a mutabilidade de objetos epistêmicos para condiçôes experimentais, conforme proposta por Rheinberger (1997). Mais uma vez, entendemos que temos aqui a possibilidade de contribuiçôes para a pesquisa, podendo analisar, em outros estudos, de modo mais detido, como práticas das ciências se concretizam em situaçôes de ensino; e também entendemos que estes resultados podem ser importantes para o planejamento de atividades de ensino na relação com os objetivos a serem desenvolvidos e os conhecimentos necessários para tal fim. Atividades e roteiros de ensino previamente organizados aos quais os alunos devem seguir podem privilegiar o contato dos estudantes com condições experimentais, mas não se atentam para a possibilidade de que os objetos epistêmicos sejam discutidos e negociados por eles, e, assim, o trabalho condicionado apenas às dimensôes material e conceitual do conhecimento, não possibilitando que os alunos vivenciem situações em que as dimensões epistêmica e social, que marcam o empreendimento científico.

Não foi esta a situação aqui explicitada, uma vez que a construção das investigações pelas estudantes acarretou e demandou o desenvolvimento de práticas epistêmicas. Em outras palavras, o trabalho com objetos epistêmicos resultou em ações conjuntas entre as dimensões conceitual, social, material e epistêmica 
do conhecimento (Duschl, 2008; Stroupe, 2014) e o desenvolvimento destas dimensões na relação com as características epistêmicas do conhecimento científico (Windschitl et al., 2008).

Com base em tudo o que discutimos até o momento, entendemos que este estudo pode trazer contribuiçốes tanto para o ensino de Ciências como para a pesquisa em Educação em Ciências.

Em relação ao ensino de Ciências, relembramos o já mencionado trabalho com o planejamento e o replanejamento mediante avaliaçôes constantes dos caminhos de uma investigação e, sobretudo, na identificação de quando condiçóes experimentais e objetos epistêmicos transformam-se umas em outras. Isso deve permitir a identificação de como as características epistêmicas do conhecimento científico estão sendo trabalhadas com e pelos estudantes, resultando no seu envolvimento com as dimensões do conhecimento citadas ao longo da discussão conhecimento (Duschl, 2008; Stroupe, 2014).

Para a pesquisa em Educação em Ciências, entendemos que as ideias tecidas ao longo deste texto podem contribuir para aprofundar discussões teóricas sobre o ensino de Ciências como uma prática social, em que o caráter epistêmico não é meramente um componente curricular, mas um elemento central da abordagem didática do professor. As relações construídas entre apontamentos presentes nas pesquisas em ensino de ciências e aqueles trazidos por estudiosos da história e sociologia das ciências revelaram-se bastante adequado para a análise aqui empreendida e podem ser transpostas para outros estudos empíricos semelhantes.

\section{AGRADECIMENTOS}

Agradeço aos colegas do LaPEF - Laboratório de Pesquisa e Ensino de Física da Faculdade de Educação da USP pela atuação direta no processo de coleta de informações para este estudo, pelas discussóes que se revelam nestas páginas e pela leitura prévia do texto. Agradeço ao CNPq pelo financiamento obtido por meio do projeto Universal processo no. 428268/2018-8 e da bolsa Produtividade em Pesquisa processo no. 309928/2019-2 .

\section{REFERÊNCIAS}

ABD-EL-KHALICK, F., BOUJAOUDE, S., DUSCHL, R., LEDERMAN, N., MAMLOK-NAAMAN, R., HOFSTEIN, A., NIAZ, M., TREAGUST, D., \& TUAN, H. Inquiry in Science Education: International perspectives. Science Education, 88(3), p. 397 - 419. DOI: 10.1002/sce.10118. 2004.

BRASIL. Base Nacional Comum Curricular. Brasília: MEC. 2017

CARVALHO, A.M.P. Fundamentos Teóricos e Metodológicos do Ensino por Investigação. Revista Brasileira de Pesquisa Em Educação Em Ciências, 18(3), 765-794. https://doi.org/10.28976/1984-2686rbpec2018183765. 2018.

CARVALHO, A.M.P. Uma metodologia de pesquisa para estudar os processos de ensino e aprendizagem em salas de aula. In F.M.T. SANTOS \& I.M. GRECA (Org.). A pesquisa em ensino de ciências no Brasil e suas metodologias. 1a ed.Ijuí: Unijuí, v. 1, p. 13-48. 2006.

CARVALHO, A.M.P. Building up explanations in physics teaching. International Journal of Science Education, Abingdon, 26(22), p. 225-237, 2004.

CHINN, C., \& MALHOTRA, B. Epistemologically Authentic Inquiry in Schools: A Theoretical Framework for Evaluating Inquiry Tasks, Science Education, 86(2), p. 175-218. 2002.

DUSCHL, R.A., \& GRANDY, R.E. (Ed.). Teacbing scientific inquiry: recommendations for research and implementation. Roterdam: Sense Publishers. 2008.

DUSCHL, R.A. Science education in three-part harmony: balancing conceptual, epistemic and social learning goals.

Review of Research in Education, 32(1), p. 268-291. 2008. 
ERICKSON, F. Qualitative Research Methods for Science Education, In B.J FRASER \& K. G. TOBIN (Org.), International Handbook of Science Education. (pp. 1155-1173) London: Kluwer Academic Publishers. 1998.

FERRAZ, A.T., \& SASSERON, L.H. Propósitos epistêmicos para a promoção da argumentação em aulas investigativas. Investigações em Ensino de Ciências (Online), 22(1), p. 42-60. 2017.

FRANCO, L.G., \& MUNFORD, D. O Ensino de Ciências por Investigação em Construção: Possibilidades de Articulações entre os Domínios Conceitual, Epistêmico e Social do Conhecimento Científico em Sala de Aula. Revista Brasileira De Pesquisa Em Educą̧ão Em Ciências, 20(u), 687-719. https://doi.org/10.28976/19842686rbpec2020u6877192020.

JIMÉNEZ-ALEIXANDRE, M.P., \& CRUJEIRAS, B. Epistemic Practices and Scientific Practices in Science Education. In: K. TABER \& B. AKPAN (Ed.). Science Education: An International Course Companion, p.69-80, Rotterdam: Sense Publishers. DOI:10.1007/978-94-6300-749-8_5. 2017.

KELLY, G.J., \& DUSCHL, R.A. Toward a research agenda for epistemological studies in science education. In Annual Meeting of the National Association for Research in Science Teaching, Nova Orleans, Louisiana, EUA. 2002.

KELLY, G. J., \& LICONA, P. Epistemic Practices and Science Education. In: M. MATTHEWS (ed.). History, Philosophy and Science Teaching, p. 139-165, Springer. DOI https://doi. org/10.1007/978-3-319-62616-1. 2018.

KELLY, G. J. Inquiry, activity and epistemic practice. In R.A. DUSCHL \& R.E. GRANDY(Ed.), Teaching Scientific Inquiry: recommendations for research and implementation (p. 288-291). Rotterdam, Holand: Taipei Sense Publishers. 2008.

KNORR-CETINA, K. Epistemic cultures: How the sciences make knowledge. Cambridge, MA: Harvard University Press. 1999.

KRASILCHICK, M. Reformas e realidade: o caso do ensino das ciências. Perspectiva, 14(1), p. 85-93. DOI: http:// dx.doi.org/10.1590/S0102-88392000000100010 2000.

LATOUR, B., \& WOOLGAR, S. Laboratory Life. The Construction of Scientific Facts. Princeton: Princeton University Press. 1986.

LEHRER, R., \& SCHAUBLE, L. Cultivating Model-Based Reasoning in Science Education. In R.K. SAWYER (Ed.), The Cambridge Handbook of the Learning Sciences (p. 371-387). Cambridge University Press. 2006.

LIDAR, M., LUNDQVIST, E., \& ÖSTMAN, L. Teaching and learning in the Science classroom: The interplay between teachers' epistemological moves and students' practical epistemology. Science Education, 90(1), 148-163. DOI: 10.1002/sce.20092 2006.

LONGINO, H. E. Science as social knowledge: Values and objectivity in science inquiry. Princeton, NJ: Princeton University Press. 1990.

LONGINO, H. E. The fate of knowledge. Princeton, NJ: Princeton University Press. 2002.

LÜDKE, M. \& ANDRÉ, M.E.D.A. Pesquisa em Educação: Abordagens Qualitativas. Temas Básicos de Educação e Ensino. São Paulo: EPU. 1986.

MANZONI-DE-ALMEIDA, D., MARZIN-JANVIER, P., \& TRIVELATO, S.L.F. Análise das práticas epistêmicas nos relatórios de grupos de alunos do curso superior durante a execução de uma atividade investigativa de imunologia. Investigaçôes em Ensino de Ciências (Online), 21(2), p. 105-120. http://dx.doi.org/10.22600/1518-8795. ienci2016v21n2p105. 2016.

NASCIMENTO, L.A, \& SASSERON, L.H., A constituição de normas e práticas culturais nas aulas de Ciências: proposição e aplicação de uma ferramenta de análise. Ensaio Pesquisa em Educação em Ciências (Belo Horizonte), v. 21, e10548. Epub Apr 25, 2019. ISSN 1983-2117. https://doi.org/10.1590/1983-21172019210104. 2019.

PICKERING, A. The mangle of practice: Time, agency and science. University of Chicago Press, Chicago. 1995.

RHEINBERGER, H.J. Toward a History of Epistemic Things. Synthesizing Proteins in the Test Tube. Stanford University Press, Stanford. 1997. 
SASSERON, L.H. Interações discursivas e argumentação em sala de aula: a construção de conclusões, evidências e raciocínios. Ensaio Pesquisa em Educação em Ciências (Belo Horizonte), 22(3), e20073, https://doi.org/10.1590/198321172020210135. 2020.

SASSERON, L.H. \& DUSCHL, R.A. Ensino de ciências e as Práticas epistêmicas: o papel do professor e o engajamento dos estudantes. Investigaçôes em Ensino de Ciências, 21(2), p. 52-67. 2016.

SASSERON, L.H. Alfabetização Científica, Ensino por Investigação e Argumentação: relações entre Ciências da Natureza e escola. Ensaio Pesquisa em Educą̧ão em Ciências (Belo Horizonte), 17(spe), 49-67. http://dx.doi. org/10.1590/1983-2117201517s04 2015.

SILVA, M.B., GEROLIN, E., \& TRIVELATO, S. A Importância da Autonomia dos Estudantes para a Ocorrência de Práticas Epistêmicas no Ensino por Investigação. Revista Brasileira de Pesquisa Em Educação Em Ciências, 18(3), 905-933. https://doi.org/10.28976/1984-2686rbpec2018183905 2018.

SILVA, J. C. \& SILVA, A.C.T. A dimensão epistêmica do discurso de um professor de Química no ensino de propriedades coligativas. Revista Electrónica de Investigación en Educación em Ciencias, v. 14, p. 14-29. 2019.

SILVA, A.C.T. Interações discursivas e práticas epistêmicas em salas de aula de ciências. Ensaio Pesquisa em Educą̧ão em Ciências, 17, número especial, p. 69-96. 2015.

SILVA, A.C.T. \& MORTIMER, E.F. Aspectos epistêmicos das estratégias enunciativas em uma sala de aula de química. Quimica Nova na Escola (Impresso), v. 31, p. 104-112, 2009.

STROUPE, D. Examining Classroom Science Practice Communities: How Teachers and Students Negotiate Epistemic Agency and Learn Science-as-Practice. Science Education, 98(3), p. 487-516. 2014.

WELCH, W.W., KLOPFER, L.E., AIKENHEAD, G.S. \& ROBINSON, J.T. The role of inquiry in science education: Analysis and recommendation, Science Education, 65(1), p. 33-50. https://doi.org/10.1002/sce.3730650106 1981.

WINDSCHITL, M., THOMPSON, J., \& BRAATEN, M. Beyond the scientific method: Model based inquiry as a new paradigm of preference for school science investigations. Science Education, 92(5), p. 941-967. 2008.

\section{NOTAS}

$1 \mathrm{Na} \mathrm{BNCC}$, a área de Ciências da Natureza refere-se aos conteúdos investigados pelas diferentes linhas da Física, Química, Biologia, Geociências e Astronomia. Para efeitos de economia na escrita, e porque é amplamente utilizado nas escolas, vamos nos referir a esta área, daqui em diante usando apenas o termo "ciências", em suas variaçóes (ensino de ciências, aulas de ciências etc).

2 À época em que a oficina ocorreu, os monitores eram: um aluno de Licenciatura em Química, um aluno de Licenciatura em Física, duas estudantes de Mestrado em Ensino de Ciências, sendo que uma delas era licenciada em Biologia e a outra, licenciada em Física, uma estudante de Doutorado em Educação, licenciada em Biologia, e um doutor em Química.

3 Laura não devolveu o TCLE assinado e, portanto, suas contribuiçốes na discussão não serão inseridas neste trabalho.

\section{Lúcia Helena Sasseron}

Livre docente em Educação. Professora Associada do Departamento de Metodologia de Ensino e Educação Comparada da Faculdade de Educação da Universidade de São Paulo (EDM-FEUSP). Coordenadora do LaPEF (Laboratório de Pesquisa e Ensino de Física) FEUSP.

Universidade de São Paulo, Faculdade de Educação, São Paulo, SP - Brasil.

E-mail: sasseron@usp.br 
Contato da autora:

Faculdade de Educação - Universidade de São Paulo Av. da Universidade, 308, sala 119, Cidade Universitária

São Paulo, SP - Brasil

CEP 05.508-040

Editor responsável:

Geide Rosa Coelho 